\title{
What Does It Mean to Orient Oneself in Science? On Ernst Mach's Pragmatic Epistemology
}

\author{
Pietro Gori, IFILNOVA, Universidade Nova de Lisboa
}

\author{
Post-print version of the paper published in \\ F. Stadler (ed.), Ernst Mach - Life, Work, Influence \\ (Vienna Circle Institute Yearbook) Dordrecht: Springer 2019, p. 525-536 \\ For quotations, please refer to the published text.
}

\section{Introduction}

At the present time, Ernst Mach's contribution to contemporary epistemology is too often neglected in the philosophical studies. Although his name appears in several writings published by influential philosophers from the twentieth century, and during the last decades some scholars dealt with Mach's legacy, he is still sometimes considered as a secondary thinker, that is, an author who contributed to the development of some interesting ideas, but whose merits are not so relevant that he should be thoroughly studied. On the contrary, Mach's role in the contemporary cultural history is quite important, and it is possible to say of the people who nowadays pay little attention to him what Einstein, a hundred years ago, wrote of the opponents of Mach - that they "scarcely know how much of Mach's way of thinking they have absorbed, so to say, with their mother's milk."1

Aim of the present paper is to shed light on Ernst Mach's role in the history of thought, from a somewhat "untraditional" point of view. The guiding lines of the research, indeed, do not come from special studies in epistemology or in the history of the philosophy of science, but rather from an investigation carried on by the German scholar Werner Stegmaier, who focused on the topic of "orientation" as characteristic feature of modern and contemporary Western philosophical culture. In his main work on that issue (Philosophie der Orientierung, 2008) Stegmaier scarcely deals with the philosophy of science, and is rather more concerned 
with questions that - only apparently - are related to a different field of study. Nevertheless, as will be shown, this is a fertile perspective for studying Mach, since it helps contextualize his investigation in the cultural debate of the final decades of the nineteenth century, thus showing some elements that otherwise would remain hidden. With no intention of pretending that Mach was someone that he himself always refused to be - i.e., a philosopher - this paper aims to stress the philosophical relevance of some outcomes of Mach's investigations, and to show that they are consistent with particular issues that pertain to modern and contemporary philosophy.

In what follows it will be argued that Mach belonged to the thematic path outlined by Stegmaier and, furthermore, that he gave an original contribution to that path by developing a pragmatic epistemology. In order to properly contextualise the paper, two premises will be needed. Section 1 will therefore be devoted to explain (a) what is the Philosophy of orientation; (b) which definition of "pragmatism" will be adopted in this paper; finally, (c) what pragmatism has to do with the problem of orientation in philosophy.

\section{Orientierung and Pragmatism}

Werner Stegmaier's Philosophie der Orientierung (2008) offers a thorough study of the meaning and use of the notion of "orientation" in modern and contemporary philosophy. According to Stegmaier, that notion played an important role in Western philosophical culture, for it is related with some issues debated since the late-eighteenth century (particularly in Germany). Furthermore, Stegmaier stresses that the German word Orientierung is recent and that its use in philosophy dates more or less two and a half centuries. That term has of course first a topographical meaning (it actually means "to look at orient", that is, "to find the east"), but it can be used in many senses, in order to describe attitudes, beliefs, ideologies, etc. In general, Orientierung means "the capacity of finding our way in a specific situation [Leistung, sich in einer Situation zurechtzufinden] and adopting solutions that allow us to have that situation in control." 2 This definition can be applied to several different fields, that is to say, orientation is not only a matter for theoretical investigation, but rather involves issues that also pertain to pragmatic (or practical) research, Ethics and Morality. ${ }^{3}$ 
The origin of the philosophical meaning of the notion of Orientierung in the Germanspeaking world can be traced back to Immanuel Kant. As Stegmaier argues, it is in Kant's writing What Does it Mean, to Orient Oneself in Thinking? (1786) that one finds a philosophically relevant use of the verbal form "to orient oneself". ${ }^{4}$ With that text, Kant contributed to a debate on Belief and Reason (Glauben and Vernunft) by adopting the idea of orientation as a pivotal concept connecting those notions. In Kant, sich orientieren can be seen as a type of make-believe which is presupposed in any activity of Reason and, therefore, is involved in the actual critique of the Reason itself. ${ }^{5}$ Leaving aside the details of Kant's 1786 text, for that would lead us far beyond the aims of the present paper, it is worth remembering the general problem that Kant was facing. That is, the problem of human knowledge and the value of make-believe, a problem that strongly influenced modern and contemporary philosophy, for it led to the heated topic of relativism (not to mention nihilism), which has been widely debated during the second half of the nineteenth century.

The importance of the notion of orientation in and for philosophy can be found in the idea that "to find our way" in the world is a fundamental necessity of the human being. Orientierung, therefore, lies at the basis of any questioning, of any posing problem itself, and it is so deeply rooted in our approach to reality that, on 1872, the German thinker Julius Baumann (that will be also mentioned in sec. 2 of the present paper) adopted the newly coined word Weltorientierung as a synonymous of "philosophy". ${ }^{6}$ To put it briefly, the idea is that, at any level of his activity (theoretical, practical, etc.) the human being has to do with a potential disorientation, for contemporary philosophers questioned the actual existence of the reference points of our world description and interpretation. From that viewpoint, one can interpret the several forms of relationship of the human being with the external world as attempts to provide means for the orientation. These forms include religion, art, and ethics but also science, which should not be seen as separated from the general philosophical thought (as nowadays sometimes happens).

In his reconstruction of the presence of the theme of orientation in philosophy, Stegmaier indeed devotes some sections to the role that signs (Zeichen) play in our relationship with the world, and focuses especially on logic and scientific thought. For him, concepts, names, and logical notions, all have a fundamental symbolic value, and can therefore be seen as means for an orientation in the specific fields to which they pertain, but also as tools for finding our way in the world in a broader sense. ${ }^{7}$ That view of course implies a new consideration of 
science, whose aim has not to be seen as to provide an actual knowledge of reality, but only to manage it and predict its development as well as possible. The very notion of truth, thus, acquires a quite different meaning from the one that was taught by the old schools of philosophy. According to Stegmaier, truth becomes a kind of regulative idea, an ideal objective of research: as he argues, "truth is the escape point [Fluchtpunkt] of scientific orientation, the point towards which she is oriented." 8

The meaning of what above stated will be clearer when Ernst Mach's position will be taken into account (sect. 2 and 3). As for now, let us consider the second premise of this paper, that is, pragmatism. In what follows, pragmatism will be considered from a broad point of view, as an inclusive philosophical research program. In particular, pragmatism can be seen as a peculiar reaction to the problem of the meaning of ideas and truth, that is, as a strategy for dealing with a disorientation which is epistemological as much as practical. As argued by William James in the chapter of The Meaning of Truth titled Humanism and Truth, pragmatism arises from the development of modern epistemology and faces the relativism implied in "the break-down which the last fifty years have brought about in the older notions of scientific truth." According to James, the "multiplication of theories" in the second half of the nineteenth century led to a sceptic view of the value of scientific laws and concepts; as a result, these laws and concepts should be treated only as "conceptual shorthand, true so far as they are useful but not farther." 10 In order to avoid that scepticism and any kind of epistemological nihilism, it is necessary to find a way to manage relativism and, if possible, also to make it productive. That was the aim of several epistemologies that have been developed during the late-nineteenth and the early-twentieth century, research programs that shared a positive attitude towards the relativism above mentioned and that worked out comparable methods for determining the value of ideas with no truth-value. As Christophe Bouriau recently argued, these methods are pragmatic at their very core, insofar as they are grounded on the belief "that from the positive practical implications of certain ideas, the value of these ideas may be determined, such implications being conceived in terms of operational convenience and of fruitfulness." 11

As final preliminary remark, it is worth noting that pragmatism, thus conceived, is deeply concerned with several fundamental features of the "philosophy of orientation". From a general point of view, indeed, pragmatism contributed to contemporary philosophy by focusing on the problem of providing means for finding our way in the world, thus facing the 
same disorientation Stegmaier talks about in his volume. Moreover, pragmatism considers as a primary criterion for evaluating ideas and theories precisely their operational fruitfulness as means for describing and managing the world - that is to say, for orientation. Finally, the most important pragmatist thinkers (e.g. Peirce and James) have been concerned with the specific topics of signs and - in particular - truth, and the outcomes of their reflections are consistent with Stegmaier's argument.

\section{The task of philosophical and scientific thought}

Given these premises, it is now possible to address the question: What does Mach have to do with the "philosophy of orientation"? As will be argued, more than one can imagine.

In talking about scientific knowledge, Ernst Mach is especially as much as explicitly concerned with the problem of orientation. In the final section of the first chapter of the Analysis of Sensations, for example, he states that "the biological task of science is to provide the fully developed human individual with as perfect means of orientating himself as possible [eine möglichst vollstandige Orientirung]." ${ }^{12}$ Some years later, in a paper on Sensory Elements and Scientific Concepts (1910), Mach sums up his view on the elements and their "dependence upon a complex of elements which includes one's own body," and then argues: "Only in so far as we establish the dependence of the elements on one another and explore those connections, whose stability is determined by the elements, can we orient ourselves in the world [in der Welt orientieren]."13 These excerpts already show that Mach adopted the terminology that pertains to the thematic field investigated by Stegmaier, that is to say, Mach uses the term Orientierung with a meaning that is not topographical, and he does so with regard to an intellectual activity of the highest level. Moreover, Mach proves to be concerned with the same fundamental problem that characterizes modern and contemporary Western culture and that gives philosophical value to the theme of orientation: namely, the lack of absolute and unchanging reference points (that is, truths) of human knowledge.

If one wants to explore the possibility of relating Mach with the Philosophie der Orientierung, the most interesting textual evidence can be found in the first chapter of Knowledge and Error (1905). That chapter is devoted to Philosophical and Scientific Thought, and in its opening sections Mach presents some observations on human knowledge from an evolutionary point of view. In the fourth paragraph, Mach deals with scientific 
thought (wissenschaftliche Denken), which, in his view, "presents itself in two seemingly different forms: as philosophy and as specialist research." Then, Mach argues:

The philosopher seeks to orient himself as completely and comprehensively as possible [sucht eine möglichst vollständige, weltumfassende Orientierung] in relation to the totality of facts, which necessarily involves him in building on material borrowed from the special sciences. The special scientist is at first concerned only with finding his way [um Orientierung und Übersicht ... zu tun] about a smaller area of facts. Since, however, facts are always somewhat arbitrarily and forcibly defined with a view to the momentary intellectual aim, these boundary lines are constantly shifting as scientific thought advances: in the end the scientist too comes to see that the results of all other special enquiries must be taken into account, for the sake of orientation [Orientierung] in his own field. Clearly in this way special enquirers also collectively aim at a total picture [eine Weltorientierung] through amalgamation of all special fields. Since this is at best imperfectly attainable, this effort leads to more or less covert borrowings from philosophical thought. The ultimate end of all research is thus the same. ${ }^{14}$

In this excerpt Mach talks again of "orientation" as task of both philosophers and special scientists, and uses the German word Orientierung as he did in other writings. Nevertheless, the passage contains something more, namely a hidden reference that is fundamental for the aim of the present paper. At the end of the quoted excerpt, Mach talks of the "total picture" that the special enquirers collectively aim at gaining. In the original German version of Knowledge and Error, Mach uses the word Weltorientierung (italics by Mach), a term that appears only here in his whole writing. This isolated case cannot be by chance, and in fact it is revealing. As mentioned in the previous section of this paper, the word Weltorientierung first appeared in the German speaking world in Julius Baumann's book Philosophie als Orientirung über die Welt. Baumann is an author scarcely known in modern times, but that at the end of the nineteenth century played his part in the philosophical debate. ${ }^{15}$ If one looks at the pages of Baumann's book where that word appears, it is easy to see that the questions there explored are exactly the same as those Mach deals with in the above quoted passage from Knowledge and Error.

Baumann, indeed, talks of Weltorientierung in the preface of his 1872 book. In that text, Baumann defends the idea that philosophy actually means "general orientation in the world through thought." 16 Moreover, Baumann argues that philosophy gains an important aid from scientific thought (wissenschaftliche Nachdenken), and he then deals with the relationship between scientific philosophy and the special sciences. ${ }^{17}$ For Baumann, the only difference 
between philosophical and scientific thought concerns the limits of their application. While philosophy aims to reach a general and universal knowledge, each special science deals with a limited portion of the world, and can therefore only gain an orientation that will be restricted to these portions ("wir haben in ihnen blos Orientierungen über einzelne Theile der Welt"). ${ }^{18}$ Of course, if we collect the outcomes of all the special sciences, the result will be a general overview of the world. In other words: "Each science, if separated from the others, provides us with a limited orientation in the world [ein Stück Weltorientierung], while all the sciences taken together can provide us with a complete orientation [die Ganze Weltorientierung]."19 What the orientation provided by the special sciences lacks is the general and universal perspective that pertains only to philosophy, which, in Baumann's view, remains at the very edge of the pyramid of human knowledge.

As above suggested, there is a striking similarity between Baumann's and Mach's texts. Both the authors deal with the relationship between philosophy and special sciences, that they both consider as an expression of scientific thought in general. Moreover, the task that both Baumann and Mach attribute to these disciplines is also the same - namely, to provide man with a general orientation in the world (Weltorientierung). Thus, although there is no actual proof that Mach read Baumann's 1872 book (unfortunately, the text does not appear among Mach's documents stored at the Deutsches Museum in Munich), there are good reasons in support of the idea that Philosophie als Orientirung über die Welt is the hidden reference of the quoted passage from Knowledge and Error. Moreover, it can be argued that Mach's concerning with orientation in and through science should not be seen as a minor topic of his epistemological investigation.

\section{Pragmatic epistemology}

What has been considered above supports the idea that Mach belongs to that section of the history of Western culture and philosophy outlined by Stegmaier's Philosophie der Orientierung. ${ }^{20}$ This idea is corroborated by the fact that Mach gave an original contribution to that history, that contribution consisting in the value and function Mach attributed to scientific concepts - which are the actual means of orientation. An investigation on Mach's view of scientific concepts will therefore answer the question: What does it mean, for Mach, to orient oneself in (and through) science? 
To address that question allows us to define what can be called "Mach's pragmatism". An investigation of the nature and role of scientific concepts and theories, and, consequently, of the meaning of scientific "truths", actually pertains to the research program that arose during the second half of the nineteenth century and to which William James gave a collective name. As known, James has been particularly influenced by Mach in developing his own form of pragmatism. The overlapping of Mach's views on psychology and epistemology with those defended by James has been stressed by authors who personally knew Mach (e.g. Hans Kleinpeter and Philipp Frank), ${ }^{21}$ and during the last decades studies have been devoted to that topic, in order to show the "state of elective - but also selective - affinity" that characterized the relationship between Mach and James. ${ }^{22}$ James's considerable number of annotations in his private copies of works such as Analysis of Sensations and Knowledge and Error demonstrates his interest in Mach's investigations, and reveal the former's attempt to indicate similarities between Mach's views and his own position or current interest. ${ }^{23}$ As Gerald Holton concludes, “James's copies of Mach's book graphically demonstrate the intense impression they made on him during the period in which he was engaged in writing his own major works." ${ }^{24}$ That impression is particularly evident in James's Pragmatism, where the debt to Mach is explicitly mentioned..$^{25}$ In general, it is possible to say that jamesian pragmatism is deeply grounded on machian basis, and that is why Mach himself, in a famous letter he sent to James on June 28, 1907, admitted: “Although I am by my entire training a scientist and not at all a philosopher, nevertheless I stand very close to pragmatism in my ways of thinking, without ever having used that name." 26

Ralph Perry stated that "from Mach, James had learned something of what he knew about the history of science, and he had readily accepted his view of the biological [evolutionary] and economic function of scientific concepts." ${ }^{27}$ Both these elements are fundamental features of Mach's pragmatic epistemology that can be found at the origin of his idea that science provides "the fully developed human individual with as perfect means of orientating himself as possible". ${ }^{28}$ In Knowledge and Error, Mach argues that concepts are mental constructs produced by a process of abstraction, thought symbols that "enable man to classify the real." ${ }^{29}$ According to him, "concepts [are] so valuable and useful for science, [for] they can represent and symbolize in thoughts large areas of fact. The purpose of concepts is to allow us to find our way in the bewildering tangle of fact [in der verwirrenden Verwicklung der Tatsachen sich zurecht zu finden]. ${ }^{, 30}$ It is easy to see that Mach is in total agreement with 
the perspective of a Philosophie der Orientierung. "The capacity of finding our way [zurecht finden] in a specific situation" is actually the definition of Orientierung (see above, sec. 1), and in dealing with concepts Mach focuses on the same symbolic value that Stegmaier stresses, when he talks about the role and function of signs in the scientific discourse. Nevertheless, as mentioned above, Mach's view of the scientific concepts presents some original features that can be stressed by making reference to other writings where he deals with that same topic.

It is well-known that Mach defended an evolutionary conception of knowledge, according to which science is the final product of an intellectual development. Within that framework, concepts are but "mental symbols for groups of sensations - symbols that do not exist outside our thought". ${ }^{31}$ Therefore, in Mach's view, scientific concepts do not correspond to external reality, that is to say, they do not describe reality as it is in itself. The anti-realistic picture that can be drawn from Mach's statements on the economical nature of physical inquiry that is, the idea that the name we give to a group of properties is nothing "more than a compendious economical symbol" - is mitigated by his famous view of the adaptation of thoughts to facts and of thoughts to one another. ${ }^{32}$ If literally applied to epistemology, the Darwinian model suggests that thoughts are shaped accordingly to external reality, whose general features could therefore be inferred from the attributes of thoughts themselves. This hypothetical realism is a kind of "third way" between realism and anti-realism, and helps dealing with an issue that, in Mach, is not always so clear. ${ }^{33}$ However, this latter dichotomy can be addressed in a different way, which is precisely what I think Mach did.

Concepts, according to Mach, are a creation of human thought whose relationship with facts cannot be neglected. Therefore, concepts are not a product of pure imagination, but at the same time they do not just reflect the external world. The original contribution of Mach to that topic consists in leaving aside the content of scientific concepts (the portion of reality they should describe), and to look, instead, at the practical role they play, at the activity they represent. As Mach states in The Principles of the Theory of Heat, "the strict definition of a concept and, in case it is familiar, even the name of the concept is a stimulus to a precisely determined though often complicated, testing, comparing or constructing activity whose result, in most cases perceptible by the senses, is a term in the extension of the concept." ${ }^{34}$ For what concerns physics, in particular, concepts can be seen as "instructions for building", while "facts are the results of building". ${ }^{35}$ Moreover, in Mach's view "the concept is not a 
finished idea, but body of directions for testing some actually existing idea with respect to certain properties, or of constructing some idea from given properties. The definition of the concept, or the name of the concept, releases a definite activity, a definite reaction, which has a definite result." 36

This is a pure pragmatic epistemology. The value of a concept is not judged on the basis of what that concept represents or describes, but rather by looking at what it produces, that is, at the effects of the reaction the concept releases. This idea can be found in Mach's very definition of "knowledge" and "error". As James sums up in some marginalia at the end of Chapter 7 of his personal copy of the 1905 edition of Erkenntnis und Irrtum, "error in Mach's eyes has the exclusively practical meaning of a concept that leads to disappointment in expectation. Täuschung [deception] leads to Enttäuschung [disappointment], Wahrheit [truth] to Bestätigung [confirmation]." ${ }^{37}$ The only difference, therefore, lies in the result of each evaluation, which proves (or denies) the actual operational convenience and fruitfulness of a conception in guiding our expectations. As Mach argues in his late paper on Sensory elements and Scientific Concepts, "whether our expectation is satisfied (...) or is disappointed, in both cases the value of the concept will be determined by testing." 38 Mach's view is consistent with the thematic lines presented in the first section of this paper. As many other thinkers from the second half of the nineteenth century, Mach is concerned with a conception of human knowledge that is quite different from the traditional one, and that, by rejecting the idea that our thoughts correspond to external reality, leads to a mere relativistic view of "truth". Given that concepts and theories cannot be judged by looking at their actual content, and that man needs some principles of evaluation in order to keep on pursuing scientific research, Mach explores the same possibility other pragmatist thinkers of his time took into account and focuses on the practical consequences of ideas. As above stated, the main aim of all this is to provide man with principles of orientation in the world. For what concerns the actual orientation that, in Mach's view, scientific concepts provide us, some hints can be found in the final chapter of Knowledge and Error devoted to Sense and Value of the Laws of Nature. In that text, Mach contrasts the usual opinion "that the laws of nature are rules, which processes in nature must obey," with the idea that these laws are only the result of an abstraction from natural processes, that is to say, "our intuition and our concepts alone prescribe laws to nature." 39 That view clearly limits the normative value of the laws of nature. According to Mach, their value rests on their role of "restrictions that 
under the guidance of our experience we prescribe to our expectations," a role that stresses the biological importance of these laws, which is coherent with the general evolutionary conception of science defended by Mach. ${ }^{40}$ What is worth noting, for the aim of the present paper, is that Mach's dealing with that topic is related with the theme of orientation. Indeed, Mach argues that the "laws of nature are a product of our psychological need to find our way about [zurecht finden] in nature, so that we do not stand estranged and baffled in front of natural processes." ${ }^{41}$ Furthermore, he stresses that they must be considered only as the most recent "attempt at orientation [Orientierungsversuch]" produced by our "current state of culture". ${ }^{42}$ According to Mach, the main urge of scientific research at the beginning of the twentieth century is "to minimize mental effort, to attain economy, continuity, constancy, and as general a scope as possible for profitably applying the rules set up." ${ }^{43}$ The value of scientific laws and theories thus lies in their practical efficacy, in their operational fruitfulness as economical tools for dealing with the hitherto accumulated individual findings. "Natural science," continues Mach, "may be viewed as a kind of collection of instruments [Instrumentsammlung] for the intellectual completion of any partially given facts or for the restriction, as far as may be, of expectations in future cases." 44 As above considered with reference to the distinction between "knowledge" and "error," what is fundamental in Mach's epistemology is the role of expectations. The laws of nature are, in his view, "merely subjective prescriptions for an observer's expectations to which reality need not conform," 45 and their value can only be judged pragmatically, by looking whether those expectations are finally met or disappointed. Therefore, the role of scientific laws as instruments for finding our way about in the natural world is far from being normative. "A proposition in natural science always has a merely hypothetical sense," 46 and, as Mach concludes, "science has developed into the factor that is biologically and culturally the most beneficial" for she replaces "tentative and unconscious adaptation by a faster variety that is fully conscious and methodical. ${ }^{" 47}$ However, that does not mean that the laws that science abstracts from the natural processes can be seen as norms from which those processes cannot deviate. On the contrary, in Mach's view, the role science plays in human orientation lies in her capability of providing men with working hypotheses, with concepts that are merely mental constructs and human devices for testing some existing idea and fruitfully guiding our expectations. That is, precisely, Mach's pragmatic epistemology. 


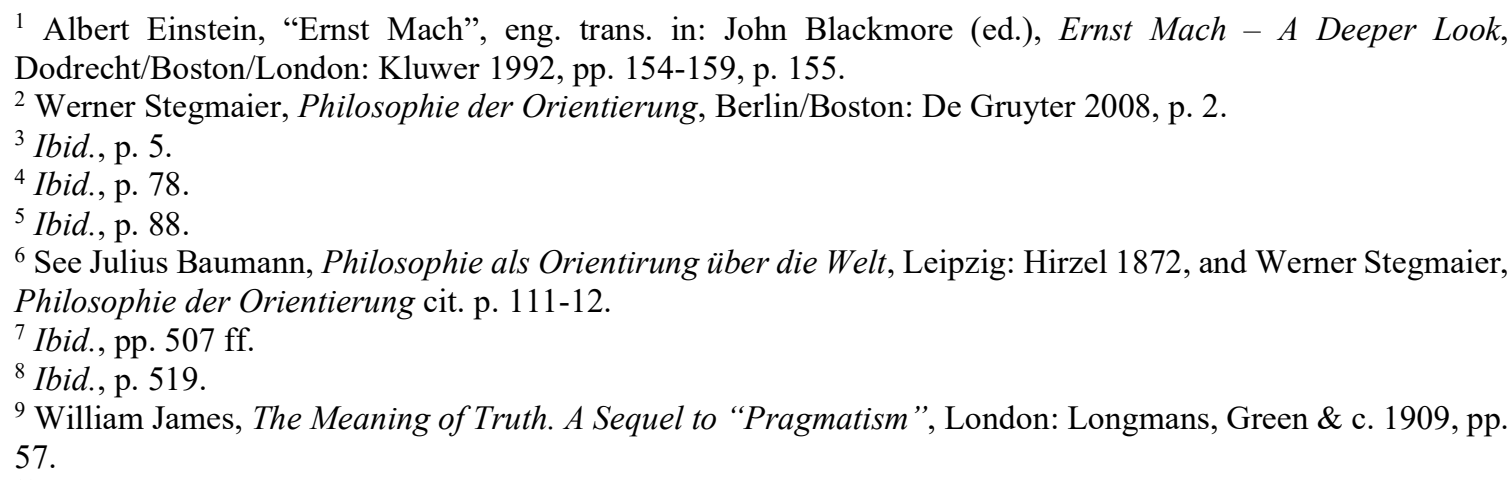

${ }^{10}$ Ibid., p. 58. See also this excerpt from 1904: "Thus has arisen the pragmatism of Pearson in England, of Mach in Austria, and of the somewhat more reluctant Poincaré in France, all of whom say that our sciences are but Denkmittel - 'true' in no other sense that of yelding a conceptual shorthand, economical for our descriptions" (James, Collected Essays and Reviews, ed. Perry, New York 1920, p. 449-450).

${ }^{11}$ Christophe Bouriau, "Vaihinger and Poincaré: An Original Pragmatism?", in: Michael Heidelberger and Gregor Schiemann (eds.), The Significance of the Hypothetical in the Natural Sciences, Berlin: de Gruyter 2009, pp. 221-250, p. 248. James was well aware of the existence of these epistemologies, and in fact he considered pragmatism as "a new name for some old ways of thinking," as we read in the title of his 1907 book. The definition presented by Bouriau aims to include Hans Vaihinger's Fictionalism and Henri Poincaré's Conventionalism among those ways of thinking, but one can also add to them Ferdinand Schiller's Humanism and Ernst Mach's Empirio-criticism.

12 Ernst Mach, The Analysis of Sensations and the Relation of the Physical to the Psychical, eng. trans. Chicago/London: Open Court 1914, p. 37.

${ }^{13}$ Ernst Mach, "Sensory Elements and Scientific Concepts", in: John Blackmore (ed.), Ernst Mach cit., pp. 118126 , p. 119. The same view of the relationship between the elements can be found in the first chapter of the Analysis of Sensations, $\S 15$, just before Mach's observation on human orientation through science.

${ }^{14}$ Ernst Mach, Knowledge and Error, eng. trans. Dodrecht/Boston: Reidel 1976, pp. 2-3.

${ }^{15}$ Baumann also wrote a paper on Mach which first appeared in the Archiv für Systematische Philosophie (1898, pp. 44-64) and that has been later included in his book Deutsche und Außerdeutsche Philosophie der letzten Jahrzehnte (1903). On 1899, the paper - titled Über Ernst Mach's Philosophische Ansichten - received some critical remarks by Hans Kleinpeter, to which Baumann replied the same year ("Ist Mach von mir Mißverstanden worden?”, in: Archiv für Systematische Philosophie, 1899, pp. 367-369).

${ }^{16}$ Julius Baumann, Philosophie cit., p. 1.

${ }^{17}$ Ibid., pp. $12 \mathrm{ff}$.

${ }^{18}$ Ibid., p. 18.

${ }^{19}$ Ibid., pp. 18-19.

${ }^{20}$ Incidentally, it is worth noting that Stegmaier only mentions Mach in a footnote devoted to the internal ear (Ohrlabyrinth) and the physiological capacity of orientation (Orientierungsempfindungen). See Stegmaier, op. cit., p. 37 n. 5 .

${ }^{21}$ See Hans Kleinpeter, "Der Pragmatismus im Lichte der Machschen Erkenntnislehre," in: Wissenschaftliche Rundschau 1912; Id., Der Phänomenalismus. Eine naturwissenschaftliche Weltauffassung, Leipzig: Barth 1913; Philipp Frank, "Was bedeuten die gegenwartigen physikalischen Theorien fur die allgemeine Erkenntnislehre?", in: Erkenntnis, I/1930-1931, pp. 126-157.

${ }^{22}$ Gerald Holton, "Ernst Mach and the Fortunes of Positivism in America", in: Isis 83/1, 1992, pp. 27-60, p. 34.

${ }^{23}$ See Holton, op. cit., pp. 35-6 and Judith Ryan, "American Pragmatism, Viennese Psychology", in: Raritan 8, 1989, pp. 45-55.

${ }^{24}$ Holton, op. cit., p. 36.

${ }^{25}$ See e.g. William James, Pragmatism. A New Name for some Old Ways of thinking, London: Longmans, Green \& C. 1907 , pp. 57 and 190. 
${ }^{26}$ Joachim Thiele, Wissenschaftliche Kommunikation. Die Korrespondenz Ernst Machs, Kastellaun: Henn 1978, p. 175.

${ }^{27}$ Ralph Barton Perry, The Thought and Character of William James, Boston: Little, Brown 1936, p. 463 (as quoted in Gerald Holton, op. cit., p. 33).

${ }^{28}$ Mach, The Analysis of Sensations cit., 37.

${ }^{29}$ Mach, Knowledge and Error cit. p. 93.

${ }^{30}$ Ibid., p. 98.

${ }^{31}$ Mach, Popular Scientific Lectures, eng. trans. Chicago: Open Court 1897, p. 201.

${ }^{32}$ See Mach, Popular Scientific Lectures cit., chapter 10, and Ernst Mach, Principles of the Theory of Heat, eng. trans. Dodrecht/Boston: Reidel, chapter 25.

33 Supporters of hypothetical realism are, for example, Donald Campbell and Konrad Lorenz. See on this Michael Bradie, "Assessing Evolutionary Epistemology", in: Biology and Philosophy 1, 1986, pp. 401-459. It is worth noting that Campbell mentioned Mach in his seminal essay "Evolutionary Epistemology" (in: Paul Schilpp (ed.), The Philosophy of Karl R. Popper, LaSalle: Open Court, pp. 412-463). There are several elements, indeed, to consider Mach as a forerunner of the research program outlined by Campbell; among them, Mach's idea that the Darwinian theory of development can be applied to thoughts as much as to organisms (see e.g. Principles of the Theory of Heat cit., p. 351).

${ }^{34}$ Mach, Principles of the Theory of Heat cit., p. 369.

${ }^{35}$ Ibid., p. 370.

${ }^{36}$ Ibid., p. 381.

${ }^{37}$ Excerpt quoted in Hiebert's Introduction to Mach, Knowledge and Error, op. cit. p. XXVI. James's copy of Erkenntnis und Irrtum is conserved in the Houghton Library of Harvard University. See also Mach, Knowledge and Error cit., p. 84: "Knowledge and error flow from the same mental sources, only success can tell the one from the other. A clearly recognized error, by way of corrective, can benefit knowledge just as a positive piece of knowledge can."

${ }^{38}$ Mach, Sensory Elements cit. p. 123.

${ }^{39}$ Mach, Knowledge and Error cit. p. 351.

${ }^{40}$ Ibid., pp. 351-2.

${ }^{41}$ Ibid., p. 354.

${ }^{42}$ Ibid.

${ }^{43}$ Ibid., pp. 354-5.

${ }^{44}$ Ibid., pp. 355-6.

${ }^{45}$ Ibid., p. 358.

${ }^{46}$ Ibid., p. 356.

${ }^{47}$ Ibid., p. 361. 